\title{
Fluttering Characteristics of the Ropes and Nets as an Active Stimulating Device inside the Cod End of a Trawl Net
}

\author{
Yong-Hae Kim* \\ Institute of Marine Industry and Department of Marine Production, College of Marine Science, Gyeongsang National University, \\ Tongyoung 650-160, Korea
}

\begin{abstract}
An active stimulating device (ASD) consisting of a net panel or ropes fluttering in the turbulence inside the cod end was effective in driving fish near the cod end to reduce juvenile by-catch. The fluttering characteristics of the rope and net panel were examined by video observations and analyzed for fluttering amplitude and period in a water channel and in field experiments with a bottom trawl. The amplitude ratio of the fluttering ropes or nets in the tank test increased with the fluttering index as the diameter of the twine, mesh size, flexibility, and flow velocity changed, whereas the period decreased with the above factors. In bottom trawl experiments, the range of mean depth difference in the fluttering net panel was $12-17 \%$ of the length of the fluttering net, and the period of depth difference or three-dimensional (3D) tilt was revealed, with shorter ones ranging from 2 to $6 \mathrm{~s}$. The amplitude as depth difference and period from field measurements were similar to those of nets in tank experiments and also to the period of 3D flow velocity inside the cod end. These results could be used to design an ASD that could be used for to the cod end of actual towed fishing gear to reduce juvenile by-catch.
\end{abstract}

Key words: Codend, By-catch, Fluttering, Amplitude, Period

\section{Introduction}

By-catch is of great interest for conservation and resources management for sustainable fisheries (Gascuel et al., 2011). The existing square-mesh window and grid methods are static, passive stimuli with short periods that do not change position. An alternative method is the so-called active stimulating device (ASD), which may take the form of a conical rope array, rotating rope kite, or fluttering net panel inside the cod end, that generates variable visual stimuli for juvenile fishes in addition to flow-related effects (Kim, 2010). An ASD consisting of a fluttering net panel and ropes within the turbulence inside the cod end has been suggested as effective in reducing juvenile by-catch of red seabream and bastard halibut (Kim and Whang, 2010; Kim, 2011). An ASD that changes position with turbulence inside the cod end could generate variable fish stimuli in the form of visual, water flow, or physical contact stimuli at the free-end (flag-like) net panel or at the rope array. Thus, ASD fluttering movements with varying moving amplitude and a period could be considered an active stimulus to which fish may respond.

However preliminary experiments on the effects of ASDs by Kim and Whang (2010) and Kim (2011) resulted in limited amplitude and period analysis using a simple kind of ASD. Therefore, elements of the ASD involving fluttering movements of ropes or net panels as changed by flow velocity, materials, and length are needed to determine the optimum size and construction for field operations. In this study, basic hydrological characteristics of the rope and the net panel, particularly the fluttering amplitude and period in a water tank,
Open Access http://dx.doi.org/10.5657/FAS.2013.0101

This is an Open Access article distributed under the terms of the Creative Commons Attribution Non-Commercial License (http://creativecommons, org/licenses/by-nc/3.0/) which permits unrestricted non-commercial use, distribution, and reproduction in any medium, provided the original work is properly cited. pISSN: 2234-1749 eISSN: 2234-1757
Received 25 July 2012; Revised 9 March 2013

Accepted 1 April 2013

*Corresponding Author

E-mail: yonghae@gnu.kr 
were examined and then confirmed by field experiments with a bottom trawl.

\section{Materials and Methods}

\section{Tank experiments}

Polyamide (PA) materials of different diameters with a constant length of $70 \mathrm{~cm}$ were selected for the fluttering twine and rope, as shown in Table 1. To compare the effects of rope length, the fluttering motions of 50-, 70-, and 90-cm lengths of sample rope R2 were compared (Table 1). A bundle of 10 strands of R2 rope was also tested for comparison with a single strand. The fluttering movement in water could be affected by hydrodynamic drag and the flexibility of the materials fluttering in air (Argentina and Mahadevan, 2005) or in water (Shelley et al., 2005). Thus, drag varies according to diameter (D), aspect ratio, and mesh size (M), and flexibility varies according to $\mathrm{D}$ and the material. The flexibility of the ropes and netting was measured by the hanging method. The vertical (Y) and horizontal coordinates $(\mathrm{X})$ of freely bending 10 - or $15-\mathrm{cm}$ samples were measured with the end of the sample fixed at the end of flat board (Kim and Ha, 1987). The fluttering index was defined as DY/X for ropes and DY/LX for nets; the length of bar was defined as $\mathrm{L}=\mathrm{M} / 2$.

The fluttering panels of the nets were made from rectangular $(70 \times 40 \mathrm{~cm}) \mathrm{PA}$ netting with a hanging ratio of $95 \%$; the samples were of different diameters and mesh sizes, as shown in Table 2. The combined ASD, consisting of the fluttering net panel and ropes, included a rectangular $(70 \times 40$ $\mathrm{cm})$ PA Raschel net (Nw in Table 2) with a hanging rate of $97 \%$ and 14 pieces of braided PA rope (R2 in Table 1) at- tached at the front end of the net panel.

The model cod end was $40 \mathrm{~cm}$ in diameter and $130 \mathrm{~cm}$ in length with a hanging rate of $87 \%$; it was made of reef knot and 28-mm diamond mesh (net sample $\mathrm{Ng}$ in Table 2), as used in previous experiments (Kim and Whang, 2010). Each of the rope elements of the ASD was fixed at the center of the front cod end with PA twine (multifilament, Ø3.5 mm). The model cod end was set up in the outer observing partition (L $2.0 \times$ B $0.8 \times$ D 0.7 ) of a circular water tank (diameter $5 \mathrm{~m}$, depth $70 \mathrm{~cm}$ ), with vertical rectified plates in front of the observing partition, as shown by Kim and Whang (2010). Turbulent flow was generated by four underwater pumps (IPV-835, 220 V, $1 \mathrm{hp}$; Hanil Electronics, San Diego, CA, USA) at a mean velocity of $0.6 \mathrm{~m} / \mathrm{s}$ and seven pumps with a mean velocity of $0.8 \mathrm{~m} / \mathrm{s}$ measured by a flow meter (201D; Marsh McBirney, Frederick, MD, USA).

Fluttering of the ASD was observed with an underwater video camera (Simrad OE 1210; Optronics, Oslo, Norway and OE1358; DeepSea Electronics, Rockford, IL, USA) and was recorded on videotape for $20 \mathrm{~min}$ at each flow velocity. The amplitude of ASD fluttering was defined as the distance between the upper point and lower point of the free end of the ASD, which was estimated from lateral-view video images after a calibration between the image size and the real scale. The amplitude ratio was represented as the percentage of amplitude to length of the ASD. Then, the period of the ASD was measured at a interval of $0.01 \mathrm{~s}$ from one upper point to the next upper point. The $3 \mathrm{D}$ flow velocity at the middle part of the observed section was measured by Vector (resolution $1 \mathrm{~mm} / \mathrm{s}$; Nortek, Vangkroken, Norway) at a sampling rate of $16 \mathrm{~Hz}$ for $5 \mathrm{~min}$. The 3D flow was defined in terms of towing direction $\mathrm{Vx}$, perpendicular direction $\mathrm{Vy}$, and depth direction $\mathrm{Vz}$, and the periodicity of each direction was analyzed using

Table 1. Specifications of the experimental ropes as elements of ASD

\begin{tabular}{cclccc}
\hline Designation & $\begin{array}{c}\text { Diameter } \\
(\mathbf{D}, \mathbf{m m})\end{array}$ & Material & $\begin{array}{c}\text { Horizontal bend } \\
(\mathbf{X}, \mathbf{m m})\end{array}$ & $\begin{array}{c}\text { Vertical bend } \\
(\mathbf{Y}, \mathbf{m m})\end{array}$ & $\begin{array}{c}\text { DY/X } \\
(\mathbf{m m})\end{array}$ \\
\hline R1 & 2.06 & PA, twist & 40 & 90 & 4.6 \\
R2 & 3.06 & PA, braided & 70 & 70 & 3.1 \\
R3 & 3.31 & PA, twist & 49 & 82 & 5.5 \\
R4* & 5.74 & PA, braided & 145 & 29 & 1.2 \\
R5* & 7.38 & PA, braided & 148 & 32 & 1.6 \\
\hline
\end{tabular}

ASD, active stimulating device; $P A$, polyamide.

*Sample length $15 \mathrm{~cm}$ whereas the others $10 \mathrm{~cm}$.

Table 2. Specifications of the experimental net panel with sample length $10 \mathrm{~cm}$ as elements of ASD

\begin{tabular}{lccccc}
\hline Designation & $\begin{array}{c}\text { Diameter } \\
(\mathbf{D}, \mathbf{m m})\end{array}$ & $\begin{array}{c}\text { Mesh size } \\
(\mathbf{M}, \mathbf{m m})\end{array}$ & $\begin{array}{c}\text { Horizontal bend } \\
\mathbf{( X , ~ m m )}\end{array}$ & $\begin{array}{c}\text { Vertical bend } \\
(\mathbf{Y}, \mathbf{m m})\end{array}$ & $\mathbf{D Y} / \mathbf{L X}$ \\
$\mathrm{Nw}$ (Raschel) & 0.55 & 10.5 & 35 & 90 & 0.27 \\
$\mathrm{Nb}$ (Raschel) & 1.02 & 16.0 & 35 & 80 & 0.37 \\
$\mathrm{Ng}$ (Knot) & 0.55 & 27.5 & 25 & 92 & 0.15 \\
$\mathrm{Nr}$ (Knot) & 1.26 & 27.5 & 15 & 92 & 0.57 \\
\hline
\end{tabular}

ASD, active stimulating device. 


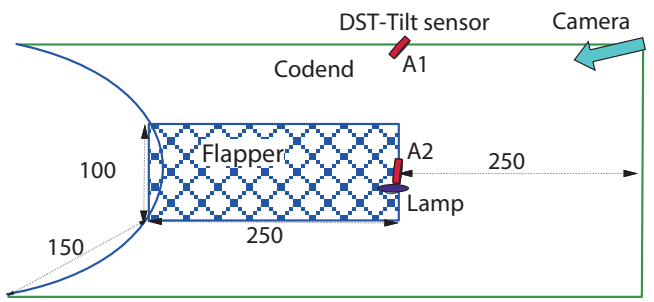

Fig. 1. Schematic view of setting up the fluttering net panel in the codend of the bottom trawl. Values are presented as $\mathrm{cm}$.

the fast Fourier transformation (FFT) method in MATLAB software (Natick, MA, USA).

\section{Field experiments with a bottom trawl}

The experimental fishing gear was a bottom trawl towed by a $999 \mathrm{G} / \mathrm{T}$ training stern trawler (Saebada, 3000 HP; Gyeongsang National University,Jinju,korea). The head rope measured $45.2 \mathrm{~m}$, the ground rope was $57.2 \mathrm{~m}$, and the total length was $59 \mathrm{~m}$. The cod end was made from double $90-\mathrm{mm}$ diamond mesh composed of 5.7-mm-thick polyethylene (PE); it was 140 mesh in length and had a 160 mesh circumference. The estimated length and diameter of the cod end during towing were $12.3 \mathrm{~m}$ and $2.5 \mathrm{~m}$, respectively.

Fluttering panels of netting were made from rectangular $(250 \times 100 \mathrm{~cm})$ PA net with a hanging ratio of $97 \%$, a diameter of $1.26 \mathrm{~mm}$, and a mesh size of $27.5 \mathrm{~mm}$, as shown for sample $\mathrm{Nr}$ in Table 2. The fluttering net panel was attached horizontally at $6 \mathrm{~m}$ from the end of cod end by $150 \mathrm{~cm}$ of string (diameter $3 \mathrm{~mm}$, PA braided twine), as shown in Fig. 1.

The fluttering net panel was recorded with a mini-camcorder $(\mathrm{L} 65 \times \mathrm{B} 25 \times \mathrm{D} 10 \mathrm{~mm}$, light sensitivity $1 \mathrm{~lx}, 8 \mathrm{~Gb}$ memory) that was enclosed in a waterproof scuba lantern case (diameter $45 \mathrm{~mm}$, length $160 \mathrm{~mm}$, neutral state in seawater) and fixed at the upper end of the cod end. A flickering light (diameter $15 \mathrm{~mm}$, length $50 \mathrm{~mm}$, depth $300 \mathrm{~m}$, weight in water $3 \mathrm{~g}$ ) was attached at the end of the fluttering net panel as an indicator for the camera under dark conditions. Memory-type DST-Tilt sensors (Star-Odi, Reykjavik, Iceland) were fixed at the end of the fluttering net panel and the upper panel of the cod end to measure depth and tilt, respectively.

The dimensions of the DST-Tilt were diameter $15 \mathrm{~mm}$, length $46 \mathrm{~mm}$, weight in water $12 \mathrm{~g}$, depth $300 \mathrm{~m}$, and it measured depth sensitivity to $\pm 0.4 \%$, tilt (yaw, pitch, roll) to $\pm 1^{\circ}$, and temperature to $\pm 0.1^{\circ} \mathrm{C}$ at 1 -s sampling intervals. Field experiments were carried out offshore of Geomoon Island (Yeosu) and Sezon Island (Tongyoung) under the conditions given in Table 3. The sea was calm, and wave height was $<1 \mathrm{~m}$. The vertical displacement of the fluttering net panel inside the cod end was defined as deviations in depth differences between the two DST-Tilt sensors for each trial. The periodicity of the fluttering net panel was analyzed for vertical displacements and 3D tilt variations using the FFT method in MATLAB software.

\section{Results and Discussion}

\section{Tank experiments}

Fluttering movements of the ASD were affected by turbulence flow in the experimental water tank and wake flow inside the model cod end. The mean flow velocity and standard deviation (SD) and period, as determined by the FFT method in the water channel of the tank, are shown in Table 4 for each

Table 3. Conditions during field experiments of the bottom trawl

\begin{tabular}{|c|c|c|c|c|c|c|c|c|}
\hline $\begin{array}{c}\text { Trial } \\
\text { No. }\end{array}$ & Date & $\begin{array}{c}\text { Shooting } \\
\text { (h:m) }\end{array}$ & $\begin{array}{c}\text { Hauling } \\
\text { (h:m) }\end{array}$ & $\begin{array}{c}\text { Course } \\
\left({ }^{\circ}\right)\end{array}$ & $\begin{array}{c}\text { Speed } \\
\left(k^{6} t\right)\end{array}$ & Depth (m) & Tide & $\begin{array}{c}\text { Catch } \\
\text { (kg) }\end{array}$ \\
\hline B1 & 2011 Oct 6 & $19: 25$ & $20: 25$ & $20-25$ & $3.3-3.5$ & $90-93$ & Ebb & 140 \\
\hline B2 & 2011 Oct 7 & $04: 10$ & $05: 30$ & $210-230$ & $3.3-3.6$ & $90-93$ & Ebb & 120 \\
\hline B3 & 2011 Oct 7 & $06: 15$ & 08:00 & $210-220$ & $3.3-3.6$ & $90-93$ & Flood & 120 \\
\hline B4 & 2011 Oct 7 & $14: 30$ & $15: 30$ & $250-260$ & $3.4-3.5$ & $41-45$ & Flood & 100 \\
\hline
\end{tabular}

Table 4. Mean \pm SD of 3D velocity and periods by FFT method by number of pump used in the tank

\begin{tabular}{|c|c|c|c|c|c|c|}
\hline \multirow{3}{*}{ Flow direction } & \multicolumn{6}{|c|}{ No. of pumps } \\
\hline & \multicolumn{3}{|c|}{4} & \multicolumn{3}{|c|}{7} \\
\hline & Velocity $(\mathrm{m} / \mathrm{s})$ & Period (s) & $n$ & Velocity $(\mathrm{m} / \mathrm{s})$ & Period (s) & $n$ \\
\hline $\mathrm{Vx} \pm \mathrm{Sx}$ & $0.62 \pm 0.09$ & 6.0 & 4,928 & $0.81 \pm 0.14$ & 4.3 & 3,685 \\
\hline $\mathrm{Vy} \pm \mathrm{Sy}$ & $-0.09 \pm 0.07$ & 6.0 & 4,928 & $-0.11 \pm 0.11$ & 2.5 & 3,685 \\
\hline $\mathrm{Vz} \pm \mathrm{Sz}$ & $0.01 \pm 0.08$ & 1.4 & 4,928 & $0.03 \pm 0.11$ & 1.2 & 3,685 \\
\hline $\mathrm{Vr} \pm \mathrm{Sr}$ (resultant) & $0.62 \pm 0.05$ & 6.0 & 4,928 & $0.82 \pm 0.07$ & 4.0 & 3,685 \\
\hline
\end{tabular}

$\mathrm{FFT}$, fast Fourier transformation; $n$, number of data. 


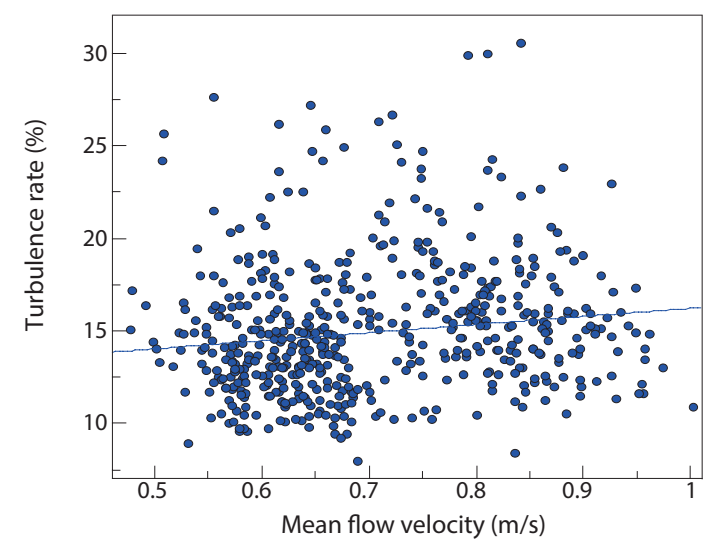

Fig. 2. The relationship between mean flow velocity and turbulence rate in water channel.

flow direction by the number of pumps used. Flow velocity was categorized into two steps (e.g., such as 0.6 and $0.8 \mathrm{~m} / \mathrm{s}$ ) according to the number of pumps ( 4 and 7 , respectively). The ratio of the SD to mean flow velocity $\mathrm{Vx}$ or $\mathrm{Vy}$, i.e., $\mathrm{Sx} / \mathrm{Vr}$ or $\mathrm{Sy} / \mathrm{Vr}$, is similar to the flow inside the cod end of a shrimp beam trawl (Kim, 2012) or bottom trawl (Kim, 2013), and the ratio of $\mathrm{Sz}(\mathrm{Sz} / \mathrm{Vr}=13-14 \%)$ was slightly higher than those values by $\operatorname{Kim}(2012,2013)$. The dominant period of flow velocity decreased slightly as velocity increased, and the $\mathrm{Vz}$ period (1-2 s) was apparently shorter than the Vx (4-6 s) or Vy (3-6 s) period.

The turbulence rate of the water channel can be represented as the square root of the mean SD divided by mean flow velocity, as shown in Fig. 2., The turbulence rate of the water channel in the present study, with a mean value of $15 \%$, was higher than the $5 \%$ rate in a circulating water tank (Pichot et al., 2009), but similar to turbulence rate and periodicity inside a shrimp beam or bottom trawl (Kim, 2012, 2013). Therefore, the water channel was reasonable for a model test of a cod end or ASD, although uneven flow distribution occurred due to the circular shape of the tank.

The mean $\pm \mathrm{SD}$ of the amplitude ratios and periods for the fluttering ropes based on flow velocity in the water channel are shown in Table 5. Most of the amplitudes and periods were not normally distributed, except the amplitude of sample R2 and the periods of sample R3 when the velocity was $0.8 \mathrm{~m} / \mathrm{s}$.
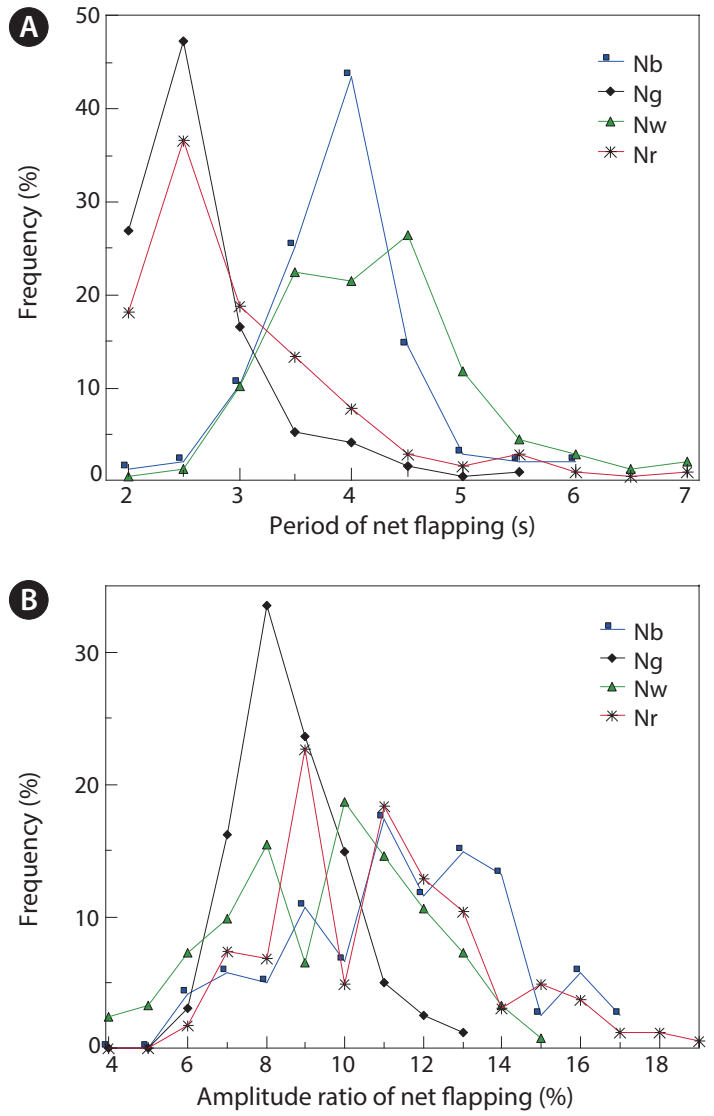

Fig. 3. Frequency distribution of period (A) and amplitude ratio (B) for fluttering net panel.

The periods of ropes were significantly different $(P<0.03$, Kolmogorov-Smirnov test) between flow velocities of 0.6 and $0.8 \mathrm{~m} / \mathrm{s}$, and the amplitude ratios of samples R4 and R5 were significantly different $(P<0.001)$ based on flow velocity.

The mean $\pm \mathrm{SD}$ of the amplitude ratio and periods for the fluttering net panel based on flow velocity in the water channel are shown in Table 6, and their frequencies are shown in Fig. 3. The amplitude frequency and the period of fluttering nets were generally not normally distributed. The periods of all net samples were significantly different $(P<0.04$, KolmogorovSmirnov test) between flow velocities or 0.6 and $0.8 \mathrm{~m} / \mathrm{s}$, and the amplitude ratios of the nets were significantly different $(P$

Table 5. Mean \pm SD of amplitude ratio and periods for the fluttering ropes by flow velocity

\begin{tabular}{|c|c|c|c|c|c|c|}
\hline \multirow{3}{*}{ Rope } & \multicolumn{6}{|c|}{ Velocity } \\
\hline & \multicolumn{3}{|c|}{$0.6 \mathrm{~m} / \mathrm{s}$} & \multicolumn{3}{|c|}{$0.8 \mathrm{~m} / \mathrm{s}$} \\
\hline & Period (s) & Amplitude (\%) & $n$ & Period (s) & Amplitude (\%) & $n$ \\
\hline $\mathrm{R} 1$ & $4.0 \pm 0.8$ & $9 \pm 3$ & 123 & $3.3 \pm 1.3$ & $10 \pm 2$ & 130 \\
\hline $\mathrm{R} 2$ & $3.8 \pm 0.9$ & $8 \pm 2$ & 122 & $2.8 \pm 0.6$ & $9 \pm 2$ & 134 \\
\hline R3 & $3.9 \pm 1.6$ & $13 \pm 5$ & 121 & $3.6 \pm 0.9$ & $13 \pm 4$ & 122 \\
\hline R4 & $4.6 \pm 1.9$ & $4 \pm 1$ & 121 & $4.3 \pm 1.8$ & $6 \pm 2$ & 122 \\
\hline R5 & $4.8 \pm 2.3$ & $6 \pm 1$ & 130 & $3.7 \pm 1.5$ & $7 \pm 2$ & 121 \\
\hline
\end{tabular}



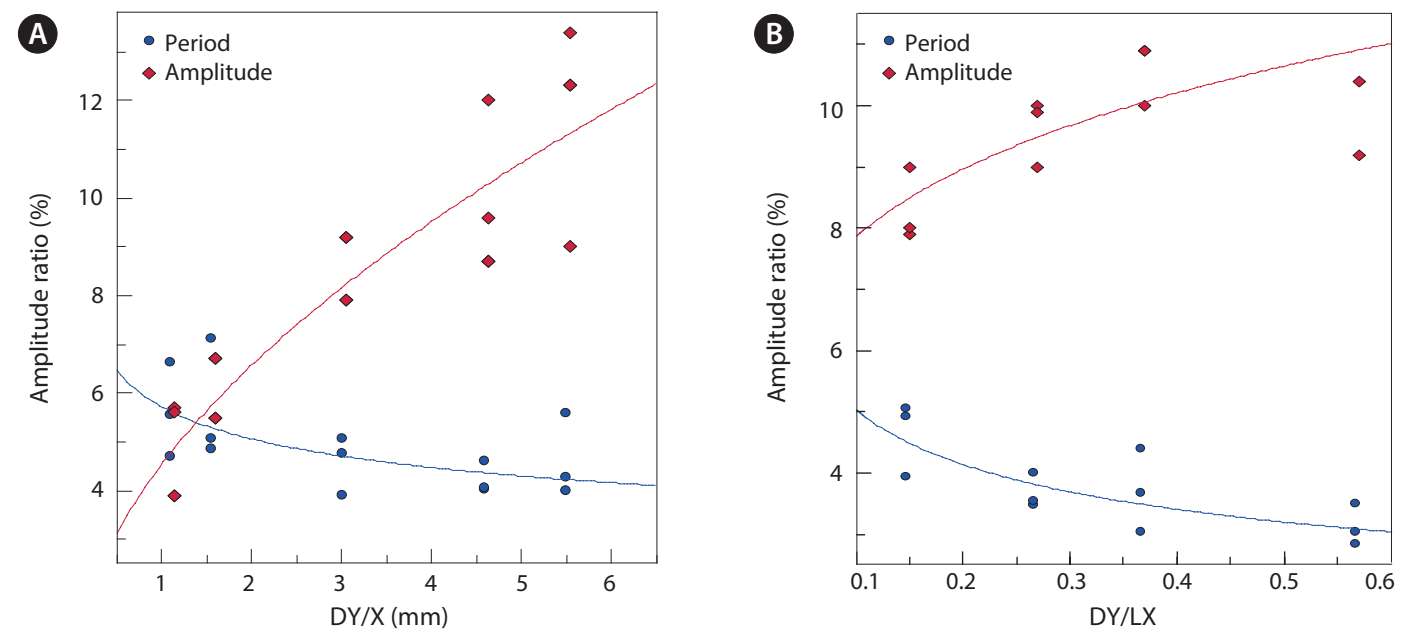

Fig. 4. The relationship between fluttering index (DY/X for ropes, DY/LX for net) and period or amplitude ratio for ropes (A) and net panel (B).

$<0.05$ ) for flow velocities of samples $\mathrm{Ng}$ and $\mathrm{Nr}$ only. The periods were significantly different between the two samples under the same flow velocity of 0.6 or $0.8 \mathrm{~m} / \mathrm{s}(P<0.0005)$, and the amplitude ratios of the samples were significantly different $(P<0.002)$, except between samples $\mathrm{Nw}$ and $\mathrm{Nr}$ at a velocity of $0.6 \mathrm{~m} / \mathrm{s}$ and $\mathrm{Nb}$ and $\mathrm{Nr}$ at a velocity of $0.8 \mathrm{~m} / \mathrm{s}$.

The mean \pm SD of the amplitude ratio (A) and the period (P) of ropes and the net panels, respectively, are represented by the fluttering indices DY/X or DY/LX in Fig. 4. Their relationship can be expressed as a power function as follows:

$$
\begin{aligned}
& \text { Ropes: } \operatorname{Ar}=4.47(\mathrm{DY} / \mathrm{X})^{0.558} \\
&(n=15, \text { correlation coefficient } r=0.93) \\
& \operatorname{Pr}=5.77(\mathrm{DY} / \mathrm{X})^{-0.177}(n=12, r=0.54) \\
& \text { Nets: } \mathrm{Ar}=11.8(\mathrm{DY} / \mathrm{LX})^{0.175}(n=12, r=0.71) \\
& \operatorname{Pr}=2.88(\mathrm{DY} / \mathrm{LX})^{-0.221}(n=12, r=0.69)
\end{aligned}
$$

The amplitude ratio of the fluttering ASD increased significantly with the fluttering index, whereas the period decreased significantly with increasing fluttering index $(P<0.05, t$-test $)$. The amplitude ratio of the fluttering ASD increased significantly with flow velocity, but the period decreased with the fluttering index, similar to a flag fluttering in air (Watanabe et al., 2002; Alben and Shelley, 2008). The amplitude ratios of the ropes can be represented for all data sets by flow velocity as follows, although other cases revealed very low coefficients due to the wide distribution, as shown in Fig. 4.

$$
\begin{aligned}
& \mathrm{Ar}=3.93(\mathrm{DY} / \mathrm{X})^{0.614}(\mathrm{~V}=0.6 \mathrm{~m} / \mathrm{s}, n=609, r=0.80) \\
& \mathrm{Ar}=5.56(\mathrm{DY} / \mathrm{X})^{0.513}(\mathrm{~V}=0.8 \mathrm{~m} / \mathrm{s}, n=609, r=0.72)
\end{aligned}
$$

Therefore, factors related to the amplitude or period of the fluttering ASD were the flow velocity and fluttering index. The intercept and slope of Eqs. 5 and 6 can be generalized by a flow velocity $(\mathrm{Vr})$ function with power coefficients $\alpha, \beta$ as follows:

$$
\operatorname{Ar}=\operatorname{Ao} \operatorname{Vr}^{\alpha}(\mathrm{DY} / \mathrm{X})^{(1-\beta \mathrm{U})}
$$

From Eqs. 5 and 6, the relevant values in Eq. 7 were estimated as Ao $=7.3, \alpha=1.2$, and $\beta=0.5$. furthermore, Ao

\begin{tabular}{|c|c|c|c|c|c|c|}
\hline \multirow{3}{*}{ Net } & \multicolumn{6}{|c|}{ Velocity } \\
\hline & \multicolumn{3}{|c|}{$0.6 \mathrm{~m} / \mathrm{s}$} & \multicolumn{3}{|c|}{$0.8 \mathrm{~m} / \mathrm{s}$} \\
\hline & Period (s) & Amplitude (\%) & $n$ & Period (s) & Amplitude (\%) & $n$ \\
\hline $\mathrm{Nw}$ & $3.4 \pm 0.5$ & $10 \pm 3$ & 123 & $4.0 \pm 0.8$ & $10 \pm 3$ & 125 \\
\hline $\mathrm{Nb}$ & $3.7 \pm 0.7$ & $11 \pm 3$ & 122 & $3.6 \pm 0.6$ & $11 \pm 3$ & 121 \\
\hline $\mathrm{Ng}$ & $3.9 \pm 1.0$ & $8 \pm 2$ & 121 & $2.4 \pm 0.6$ & $8 \pm 2$ & 163 \\
\hline $\mathrm{Nr}$ & $2.8 \pm 0.7$ & $9 \pm 2$ & 128 & $2.7 \pm 0.9$ & $10 \pm 3$ & 163 \\
\hline
\end{tabular}
may be a function of turbulence rate $(\mathrm{Tr}=15 \%)$, possibly expressed as $\mathrm{Ao} \approx 0.5 \mathrm{Tr}$, because the fluttering ratio was closely related to the turbulence rate in the tank experiments.

The means \pm SDs of the amplitude ratio and periods according to rope length (sample R2), rope bundle (sample R2), and combined net (sample Nw) and rope (sample R2) based on

Table 6. Mean \pm SD of amplitude ratio and periods for fluttering net panels by flow velocity 


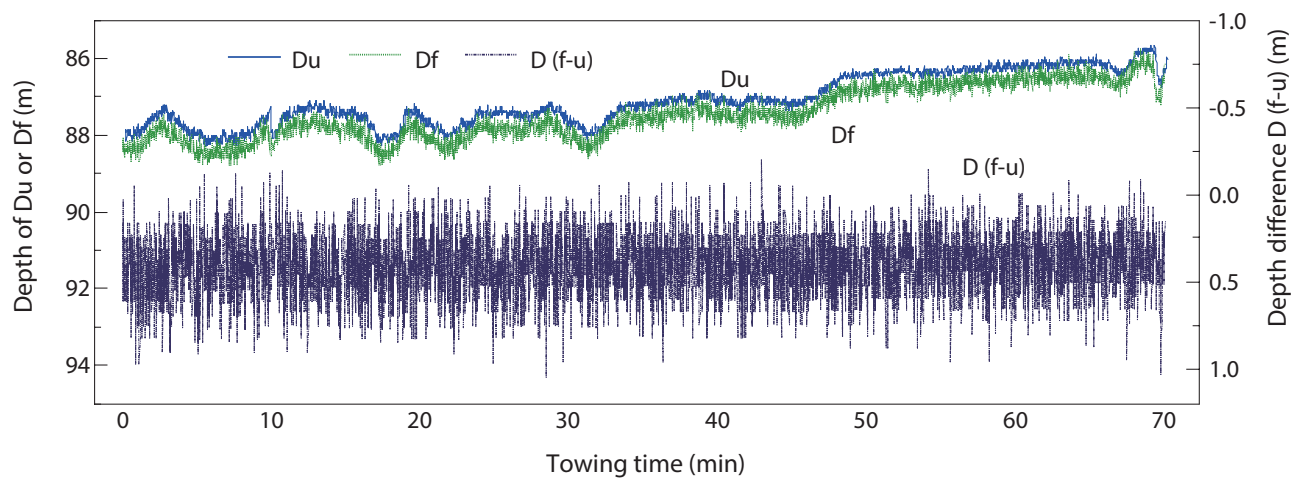

Fig. 5. An example of depths of upper codend (Du) and the fluttering net panel (Df), and deviation of depth difference D (f-u) from field experiment B1.

flow velocity in the water channel are shown in Table 7. The period of the rope bundle increased slightly with rope length, whereas the amplitude ratio remained unchanged with rope length. The period of the rope bundle was shorter than that of the single rope, but the amplitude ratio was greater than that of the single rope. The period at a flow velocity of $0.8 \mathrm{~m} / \mathrm{s}$ was shorter than that at $0.6 \mathrm{~m} / \mathrm{s}$, whereas the amplitude ratio was similar based on a flow velocity of $0.6-0.8 \mathrm{~m} / \mathrm{s}$. The amplitude ratios of the ropes and nets were $11-13 \%$, which was similar to the $\mathrm{SD}$ ratio of $\mathrm{Vz}$ in $\mathrm{Sz} / \mathrm{Vr}(13-14 \%)$ and also similar to the $15 \%$ turbulence rate in the water channel. Additionally, the period of the rope and nets was 2-5 s, which was similar to the period of the 3D flow of water in the channel, which was 1-6 s.

Only when the net (Nw) and rope (R2) were combined was the period shorter than those for rope or net alone, and the amplitude ratio was nearly twice that of the rope or net alone, similar to previous experiments on the ASD effect (Kim and Whang, 2010). The reason for this was the interaction of turbulence between the ropes and nets, which also affected the amplitude or period as well as the turbulence wake inside the cod end. Previous experiments on the ASD effect (Kim and Whang, 2010) demonstrated a very effective period and amplitude for driving fish near the upper cod end.

The amplitude and period of the rope and net fluttering movements varied not only according to the characteristics of the ASD, such as the material, diameter, length, and flexibility, but also according to the effects of the turbulent flow, such as 3D velocity, turbulence rate, and drag. The scale effects on fluttering between the model test in a water tank and a test in the field must be investigated in the future.

\section{Sea experiments with bottom trawl}

An example of variation in the depth of the upper panel of the cod end and the fluttering net panel and their depth differences in the bottom trawl (B1) field experiments is shown in Fig. 5. The depth difference for each 1-s time interval was considered vertical displacement of the fluttering net panel,

Table 7. Mean \pm SD of amplitude ratio and periods by length of ropes and combining ASD as rope + net panels by flow velocity

\begin{tabular}{|c|c|c|c|c|c|c|}
\hline \multirow{3}{*}{ Sample (cm) } & \multicolumn{6}{|c|}{ Flow velocity } \\
\hline & \multicolumn{3}{|c|}{$0.6 \mathrm{~m} / \mathrm{s}$} & \multicolumn{3}{|c|}{$0.8 \mathrm{~m} / \mathrm{s}$} \\
\hline & Period (s) & Amplitude (\%) & $n$ & Period (s) & Amplitude (\%) & $n$ \\
\hline $\mathrm{R} 2(50)$ & $2.4 \pm 0.9$ & $13 \pm 3$ & 133 & $2.1 \pm 0.7$ & $12 \pm 2$ & 131 \\
\hline $\mathrm{R} 2(70)$ & $3.4 \pm 1.4$ & $14 \pm 4$ & 132 & $2.5 \pm 1.0$ & $12 \pm 3$ & 134 \\
\hline $\mathrm{R} 2(90)$ & $3.3 \pm 1.2$ & $12 \pm 3$ & 131 & $2.6 \pm 1.1$ & $10 \pm 2$ & 135 \\
\hline $\mathrm{R} 2(70 \times 10)$ & $2.4 \pm 1.0$ & $14 \pm 3$ & 129 & $2.2 \pm 0.9$ & $14 \pm 3$ & 131 \\
\hline $\mathrm{R} 2(70 \times 14)+\mathrm{Nw}$ & $2.4 \pm 0.8$ & $27 \pm 4$ & 130 & $2.0 \pm 0.8$ & $26 \pm 4$ & 132 \\
\hline
\end{tabular}

Table 8. Depth difference \pm SD and periods by FFT method of the fluttering net panel in the codend of bottom trawl

\begin{tabular}{|c|c|c|c|c|c|c|}
\hline \multirow{2}{*}{ Trial No. } & \multicolumn{3}{|c|}{ Depth difference (m) } & \multicolumn{3}{|c|}{ Period (s) } \\
\hline & Mean \pm SD & Amplitude (\%) & $n$ & Shorter & Longer & $n$ \\
\hline B1 & $0.42 \pm 0.19$ & 17 & 4,201 & 3 & 55 & 4,201 \\
\hline B2 & $0.29 \pm 0.17$ & 12 & 4,501 & 6 & 6 & 4,501 \\
\hline B3 & $0.33 \pm 0.17$ & 13 & 4,981 & 3 & 79 & 4,981 \\
\hline B4 & $0.39 \pm 0.16$ & 16 & 2,821 & 3 & 28 & 2,821 \\
\hline
\end{tabular}

FFT, fast Fourier transformation. 

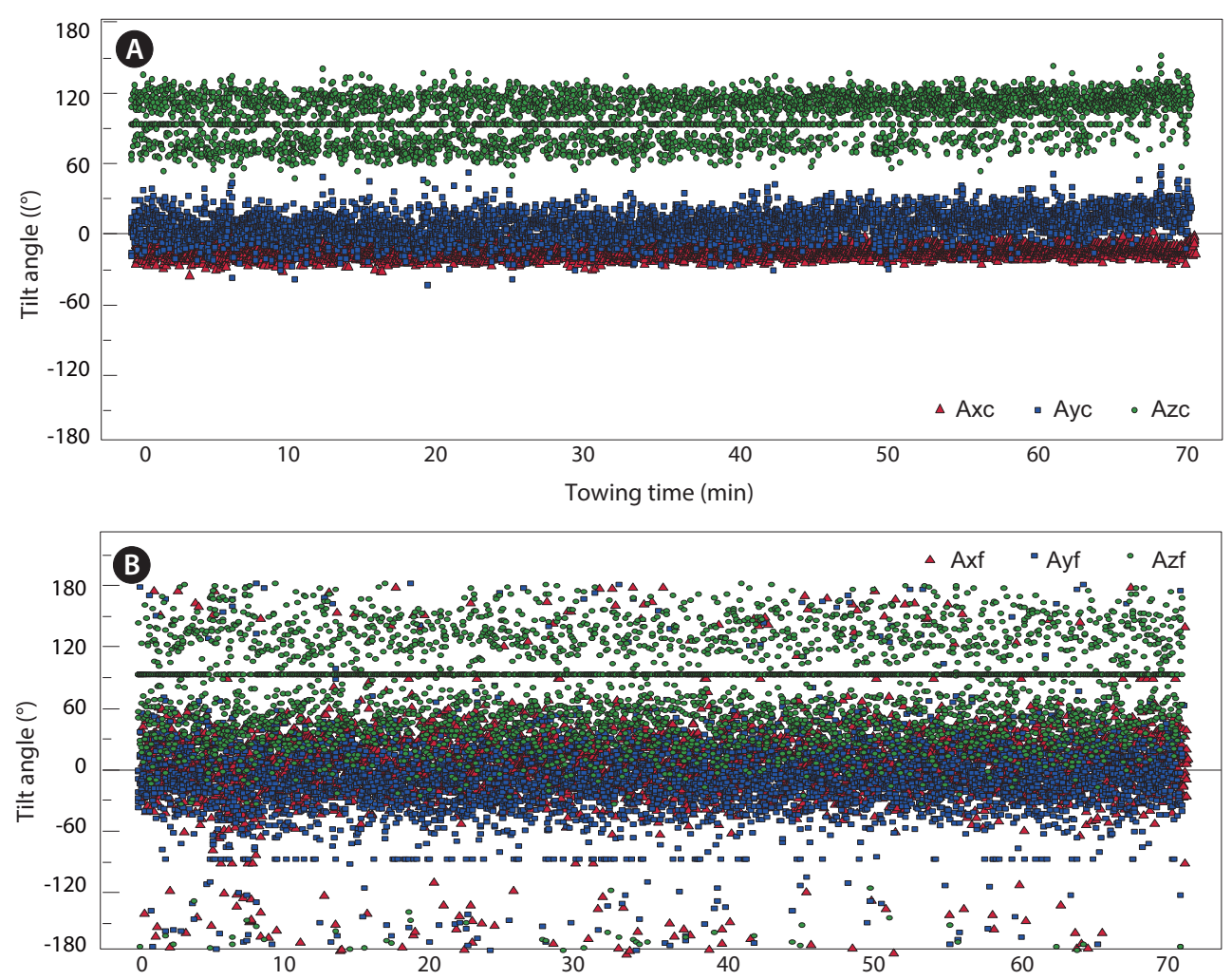

Towing time (min)

Fig. 6. Examples of 3D tilt ( $A x$, yaw; Ay, pitch; Az, roll) of upper codend (A) and fluttering net panel (B) from the field experiment $B 1$.

which varied between 0 and $1 \mathrm{~m}$. The mean depth differences and periodicity for four trials using the FFT method are shown in Table 8.

The range of mean depth difference of the fluttering net panel was $0.3-0.4 \mathrm{~m}, 12-17 \%$ of the length of the fluttering net $(2.5 \mathrm{~m})$, which was greater than that of the nets in the tank experiments. However, a maximum depth difference of about $1 \mathrm{~m}$ was reached at $40 \%$ of net length and also at $40 \%$ of the

Table 9. Mean \pm SD of 3D tilt in the fluttering net panels and upper codend of the bottom trawl

\begin{tabular}{|c|c|c|c|c|c|c|c|c|}
\hline \multirow{3}{*}{ Trial No } & \multicolumn{8}{|c|}{ Position } \\
\hline & \multicolumn{4}{|c|}{ Upper code end net } & \multicolumn{4}{|c|}{ Flapper net } \\
\hline & $\mathbf{A x}\left({ }^{\circ}\right)$ & Ay $\left({ }^{\circ}\right)$ & $\mathbf{A z}\left({ }^{\circ}\right)$ & $n$ & $\mathbf{A x}\left({ }^{\circ}\right)$ & Ay $\left(^{\circ}\right)$ & $\mathbf{A z}\left({ }^{\circ}\right)$ & $n$ \\
\hline B1 & $-13 \pm 5$ & $5 \pm 12$ & $97 \pm 19$ & 4,201 & $5 \pm 37$ & $-12 \pm 39$ & $76 \pm 50$ & 4,201 \\
\hline B2 & $-19 \pm 7$ & $18 \pm 20$ & $114 \pm 25$ & 4,501 & $37 \pm 77$ & $-59 \pm 56$ & $53 \pm 122$ & 4,501 \\
\hline B3 & $-17 \pm 6$ & $20 \pm 14$ & $116 \pm 17$ & 4,981 & $24 \pm 71$ & $-50 \pm 48$ & $75 \pm 100$ & 4,981 \\
\hline B4 & $-14 \pm 7$ & $15 \pm 16$ & $109 \pm 21$ & 2,821 & $-4 \pm 50$ & $11 \pm 50$ & $75 \pm 66$ & 2,821 \\
\hline
\end{tabular}

Table 10. The dominant period by FFT method for 3D tilt in the fluttering net panels and upper codend of the bottom trawl

\begin{tabular}{|c|c|c|c|c|c|c|c|c|}
\hline \multirow{3}{*}{ Trial No } & \multicolumn{8}{|c|}{ Position } \\
\hline & \multicolumn{4}{|c|}{ Period of upper codend (s) } & \multicolumn{4}{|c|}{ Period of flapper net (s) } \\
\hline & $\mathbf{A x}$ & Ay & $\mathbf{A z}$ & $n$ & $\mathbf{A x}$ & Ay & $\mathbf{A z}$ & $n$ \\
\hline B1 & 3 & 17 & 58 & 4,201 & 4 & 5 & 4 & 4,201 \\
\hline B2 & 3 & 26 & 26 & 4,501 & 6 & 3 & 3 & 4,501 \\
\hline B3 & 3 & 21 & 21 & 4,981 & 3 & 3 & 4 & 4,981 \\
\hline B4 & 3 & 7 & 10 & 2,821 & 2 & 7 & 3 & 2,821 \\
\hline
\end{tabular}

FFT, fast Fourier transformation. 
cod end diameter $(2.5 \mathrm{~m})$. Shorter periods of the depth differences were revealed, ranging from 3 to $6 \mathrm{~s}$, and longer periods ranging from 30 to $80 \mathrm{~s}$.

The 3D tilt variations such as yaw (Ax), pitch (Ay), and roll $(\mathrm{Az})$ of the upper panel of the cod end or fluttering net as measured by the DST-Tilt sensor are shown as examples in Fig. 6, and the mean $\pm \mathrm{SD}$ of the tilts for the four trials are shown in Table 9. The variation in the tilt of the fluttering net panel was $40-120^{\circ}$, this was greater than that in the upper panel of the cod end, which was $5-25^{\circ}$. This indicates that the end of the fluttering net panel, acting as an ASD, moved dynamically in the three directions, in addition to the depth variations noted above and in Table 8 and Fig. 5.

The periodicity of the tilts for the upper panel of the cod end and the fluttering nets are shown in Table 10. The dominant periods of the 3D tilts in the fluttering net panel were shorter, at 3-7 s, than were those of the upper panel of the cod end, with the exception of $\mathrm{Ax}(3 \mathrm{~s})$. The period range of the tilts in the fluttering nets coincided with the shorter period range of the depth difference, as shown in Table 8, although there was some difference by trials. The period range of the fluttering nets was also similar to the period range of the $3 \mathrm{D}$ flow velocity inside cod end of the trawl (Kim, 2013), although tilt and flow velocity had different sampling rates. Therefore, the period and vertical displacement of the fluttering net panel inside the cod end during the field experiments were closely related to turbulence flow.

The fluttering period of the active net panel in this study (3-7 s) could affect swimming patterns in the cod end. The dominant period of swimming acceleration for flatfish or round fish near ground gear during field operations is $4 \mathrm{~s}$ during the falling-back response and $2 \mathrm{~s}$ during the herding response (Kim and Wardle, 2006; Kim et al., 2008). Therefore, the variable period of the fluttering net panel could disturb the orderly pattern of swimming fish, particularly the acceleration time of the juvenile flatfish or red seabream, as shown in tank experiments (Kim and Whang, 2010; Kim, 2011).

\section{Acknowledgements}

Author thanks students SW Ahn and YH Cho for help in the tank experiments, and also captain and crews of the Training ship
Saebada for assistance of field experiments. This work was supported by a Korea Research Foundation Grant funded by the Korean Government (MOEHRD) (KRF-2011-0026748).

\section{References}

Alben S and Shelley MJ. 2008. Flapping states of an inviscid fluid: bistability and the transition to chaos. Phys Rev Lett 100, 074301, 1-4.

Argentina M and Mahadevan L. 2005. Fluid-flow-induced flutter of a flag. Proc Natl Acad Sci U S A 102, 1829-1834.

Gascuel D, Bez N, Forest A, Guillotreau P, Laloë F, Lobry J, Mahévas S, Mesnil B, Rivot E, Rochette S and Trenkel V. 2011. A future for marine fisheries in Europe. Fish Res 109, 1-6.

Kim YH and Ha JS. 1987. Elasticity of the funnel ribs and hydrodynamic characteristics on the sea eel pots. Bull Korean Fish Technol Soc 23, 157-162.

Kim YH. 2010. Performance of an active stimulating device using rope kite or array in the cod end to reduce juvenile by-catch. Fish Aquat Sci 13, 182-189.

Kim YH. 2011. Effects on the escapement of juvenile bastard halibut Paralichthys olivaceus of actively stimulating devices inside a model cod end. Fish Aquat Sci 14, 62-69.

Kim YH. 2012. Analysis of turbulence and tilt by in-situ measurements inside the codend of a shrimp beam trawl. Ocean Eng 53, 6-15.

Kim YH. 2013. Analysis of the turbulent flow and tilt in the codend of a bottom trawl during fishing operations. Ocean Eng 64, 100-108.

Kim YH and Wardle CS. 2006. Quantitative analysis of the swimming movements of flatfish reacting to the ground gear of bottom trawls. J Fish Sci Technol 9, 167-174.

Kim YH and Whang DS. 2010. An actively stimulating net panel and rope array inside a model cod-end to increase juvenile red seabream escapement. Fish Res 106, 71-75.

Kim YH, Wardle CS and An YS. 2008. Herding and escaping responses of juvenile roundfish to square mesh window in a trawl cod end. Fish Sci 74, 1-7.

Pichot G, Germain G and Priour D. 2009. On the experimental study of the flow around a fishing net. J Mech B/Fluids 28, 103-116.

Shelley M, Vandenberghe N and Zhang J. 2005. Heavy flags undergo spontaneous oscillations in flowing water. Phys Rev Lett 94, art. no. 094302 .

Watanabe Y, Suzuki S, Sugihara M and Sueoka Y. 2002. An experimental study of paper flutter. J Fluids Struct 16, 529-542. 